\title{
MEDIR, AMOJONAR, REPARTIR: TERRITORIALIDADES Y PRÁCTICAS DEMARCATORIAS EN EL CAMINO INCAICO DE ATACAMA (II REGIÓN, CHILE)
}

\author{
MEASURING, POSTING, ALLOCATION: TERRITORIALITY \\ AND DEMARCATION PRACTICES ALONG THE ATACAMA \\ INKA ROAD (II REGION, CHILE)
}

Cecilia Sanhueza Tohá*

\begin{abstract}
A partir del registro arqueológico de los caminos incaicos de la antigua región de Atacama (II Región, Chile), se desarrolla un análisis etnohistórico interpretativo de los denominados hitos, mojones o topus, identificados como un rasgo característico de la vialidad estatal. Desde los antecedentes aportados por la literatura colonial y los vocabularios indígenas, se incursiona en los contenidos semánticos asociados a este tipo de estructuras, estableciendo que estos aparentes señalizadores de ruta podrían estar expresando la aplicación de complejos mecanismos andinos de medición o de regulación de prácticas de desplazamiento en el Capac Ñan, así como de organización de territorialidades o espacios sociales.
\end{abstract}

Palabras claves: camino del Inka, sistemas de medición, territorialidades andinas.

Starting from archaeological records of Inka roads in the old Atacama region (2 $2^{\text {nd }}$ Region, Chile), I develop an interpretative ethnohistoric analysis concerning the so called landmarks, mojones or topus, which are been identified as typical traits of the Inka road system. Information obtained from Colonial literature and native vocabularies is used to explore semantic contents related to this kind of stone structures. It is proposed that these road-markers expressed either the application of complex, Andean mechanisms of measuring, the regulation of mobility practices through the Capac Nan or some organizational principles of social territoriality.

Key words: Inka road, system of measuring, Andean territoriality.

El deslinde o "amojonamiento" de territorios es frecuentemente mencionado en las crónicas hispanas como una de las prácticas políticas distintivas del Tawantinsuyu. Según las fuentes coloniales, el Inka redistribuía y amojonaba los espacios socioproductivos de las "provincias" en función de los intereses del culto oficial y del Estado, estableciendo aquellos que serían de usufructo estatal, regional o local. Más allá de las particularidades de cada región, y de la mayor o menor intensidad del dominio incaico local, ésta constituía una estrategia recurrente e institucionalizada que implicaba la apropiación y control no sólo de recursos, sino también de ciertos espacios políticos, sociales y rituales (Murra 1999).

La tradición oral cuzqueña suele mitificar y sacralizar la expansión estatal como un proceso de "demarcación" progresiva de los territorios, donde la figura del Inka adquiere el carácter del "diseñador" o el gran "ordenador" de la arquitectura espacial del Tawantinsuyu (Pease 1978). Se- gún los relatos míticos fundacionales del Cuzco y de los posteriores procesos de conquista, el Inka, al tomar posesión de una nueva "provincia", diseñaba o "pintaba", "medía”, "amojonaba” y "repartía" sus territorios y recursos, estableciendo así un nuevo ordenamiento del espacio social y productivo (Betanzos [1557] 1987). Las narraciones sobre el diseño y construcción de la red vial o Capac Nan parecen inscribirse también en este modelo ritualizado del proceso de conquista. Los caminos, simbólicamente concebidos como los ejes en torno a los cuales se ordenaban y organizaban las "provincias" y poblaciones del Tawantinsuyu, eran diseñados o "pintados", y luego "medidos" y "amojonados" (Betanzos 1987:81, 90; Cieza [1553] 1985:41-42).

No obstante el profundo contenido mítico y metafórico de estos relatos, y su estrecha vinculación con una concepción sacralizada del espacio geográfico, la administración española en ciertos casos reconoció o validó las demarcaciones incai-

* Universidad de Chile. csanhueza@ hotmail.com 
cas como deslindes jurisdiccionales. Así también, sus caminos fueron descritos por los viajeros y cronistas como un complejo sistema vial organizado y señalizado según determinadas técnicas de medición de distancias (Bertonio [1612] 1984; Cieza 1985; González Holguín [1608] 1952; Guamán Poma 1992).

¿A partir de qué categorías culturales se organizaban estos sistemas de demarcación, medición y organización de espacios, territorialidades y distancias?

La materialidad de la vialidad estatal y su infraestructura asociada (tambos, chasquihuasis, hitos demarcatorios, apachetas u otras manifestaciones viales de carácter logístico o ritual) da cuenta de determinadas estrategias de organización y control de espacios o territorios, así como de regulación de la circulación de hombres y recursos (Hyslop 1992). La posibilidad de establecer una relación dialógica entre esa materialidad y la documentación histórica permite aproximarse a los fundamentos ideológicos y categorías culturales que sustentaron estas prácticas de organización del espacio, y aportar a un análisis sobre las formas de dominio político, social y económico utilizadas por el Tawantinsuyu.

Desde esta perspectiva, nuestro propósito es abordar y discutir la aplicación de ciertas prácticas específicas de demarcación territorial en los caminos incaicos de la antigua Atacama (II Región, Chile), particularmente en las zonas del río Loa Superior y del gran Despoblado. Según el registro arqueológico efectuado en varios tramos de caminos de esta extensa región desértica, la presencia de estructuras de piedra denominadas "hitos", "mojones" o "tupus" constituye un componente característico de la vialidad incaica y suele atribuirse a una finalidad de señalización de la ruta (Hyslop 1992, Niemeyer y Rivera 1983). Sin desmedro de esa funcionalidad, creemos que estos dispositivos manifiestan lo que podría ser una nomenclatura bastante más compleja, asociada a mecanismos de medición y demarcación de territorios, y a formas de organización espacial del desplazamiento en el Capac Nan.

\section{"Hitos", "Mojones" o "Tupus". Una Primera Lectura Arqueológica y Etnohistórica Comparativa}

El camino incaico que recorre longitudinalmente la región del río Loa, desde Lasana hacia el norte, está trazado en plena pampa desértica por la ladera oeste del cañón, en forma más o menos paralela a su curso. En algunos de sus tramos es posible observar la presencia de apilamientos o columnas de piedras, emplazadas a uno o a ambos costados del camino. En ciertos casos se trata de hitos de factura aparentemente improvisada; en otros, de estructuras troncopiramidales o cilíndricas cuidadosamente elaboradas (Berenguer et al. 2004) (Figuras 1 y 2). En términos generales, coinciden con las descripciones efectuadas por diferentes autores en el extenso tramo del camino incaico del Despoblado de Atacama, ubicado más al sur (Hyslop 1992; Niemeyer y Rivera 1983).

Los "hitos" o "tupus" han sido definidos como estructuras de piedra de tamaños variables (con una altura promedio de $1 \mathrm{~m}$ ), que pueden presentarse en forma aislada o solitaria a uno u otro costado del camino; o en parejas, dispuestas en ambos extremos. Su distribución suele ser muy irregular, habiendo segmentos de varios kilómetros en que prácticamente no se registran, y otros donde se suceden en espacios reducidos, incluso en fracciones de kilómetro. De allí que se haya concluido que estaban destinados a servir de guía o señalización de la ruta (Niemeyer y Rivera 1983:139-143). Hyslop, por su parte, señala que este tipo de hitos constituye una técnica incaica especialmente aplicada en superficies desérticas y arenosas. Los define como pilas de piedra que, originalmente, fueron pequeñas columnas de aproximadamente un metro de altura, que indicaban el camino. Concluye que éstas no pueden considerarse como tupus (o asociarse a sistemas de medición), puesto que en algunos tramos están situadas en forma muy irregular o con mucho mayor frecuencia de lo que podría esperarse, según fueron descritas por los cronistas $(1992: 61,174)$.

Por su parte, Lynch (1995:191-192), al registrar este tipo de estructuras en los caminos del Despoblado y de la zona de Río Grande y Catarpe (San Pedro de Atacama), aporta una interpretación diferente al consignar que, al menos en ciertos casos, estos hitos podrían estar deslindando distritos administrativos o señalando una determinada organización territorial para la construcción y mantenimiento del camino. Sin embargo, hasta el momento, no se ha llevado a cabo una investigación arqueológica sistemática al respecto. 


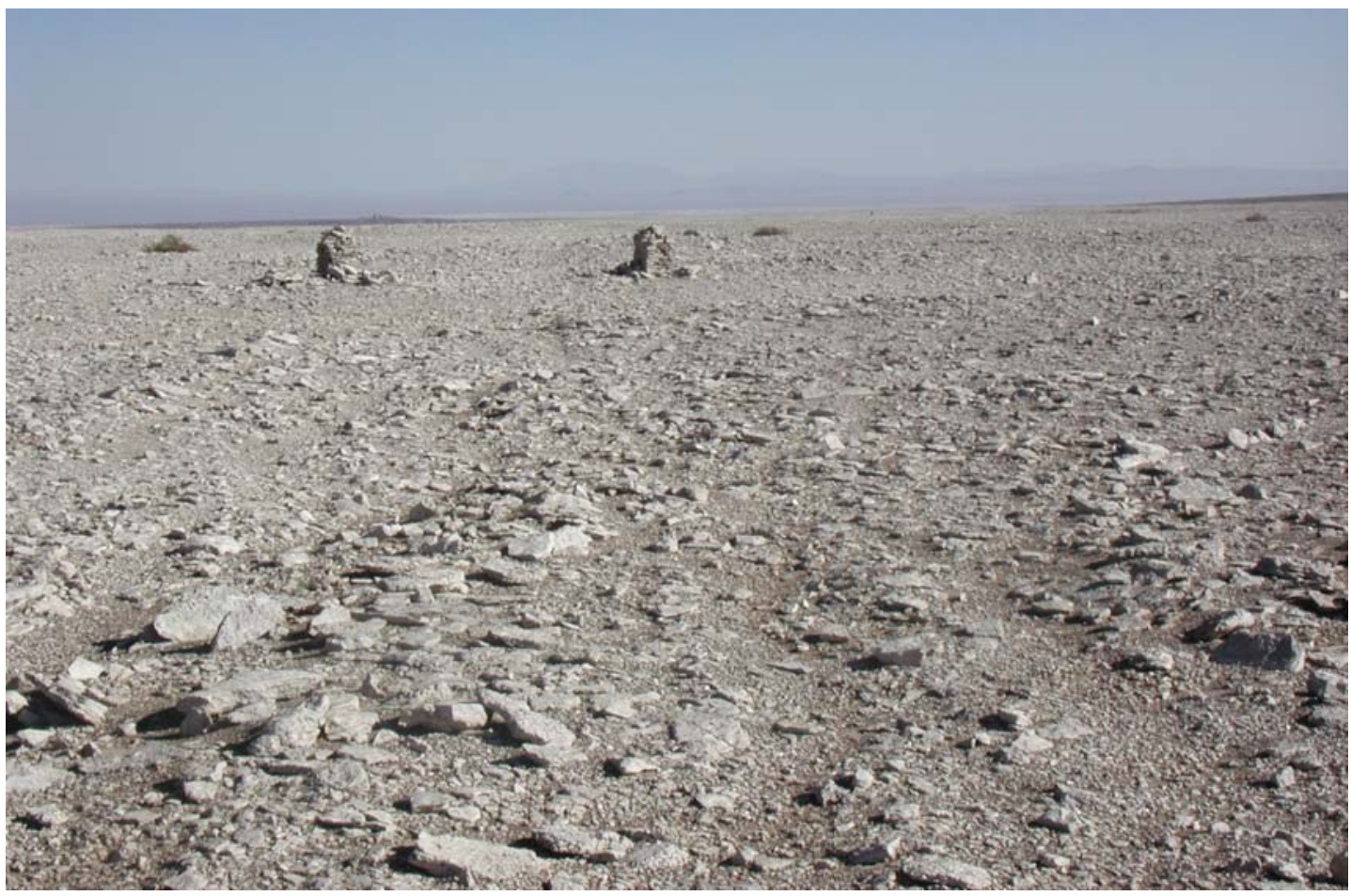

Figura 1. Hitos o columnas en el camino incaico del río Loa (Lasana).

Columnar landmarking in the Inka road on the Loa river (Laspana).

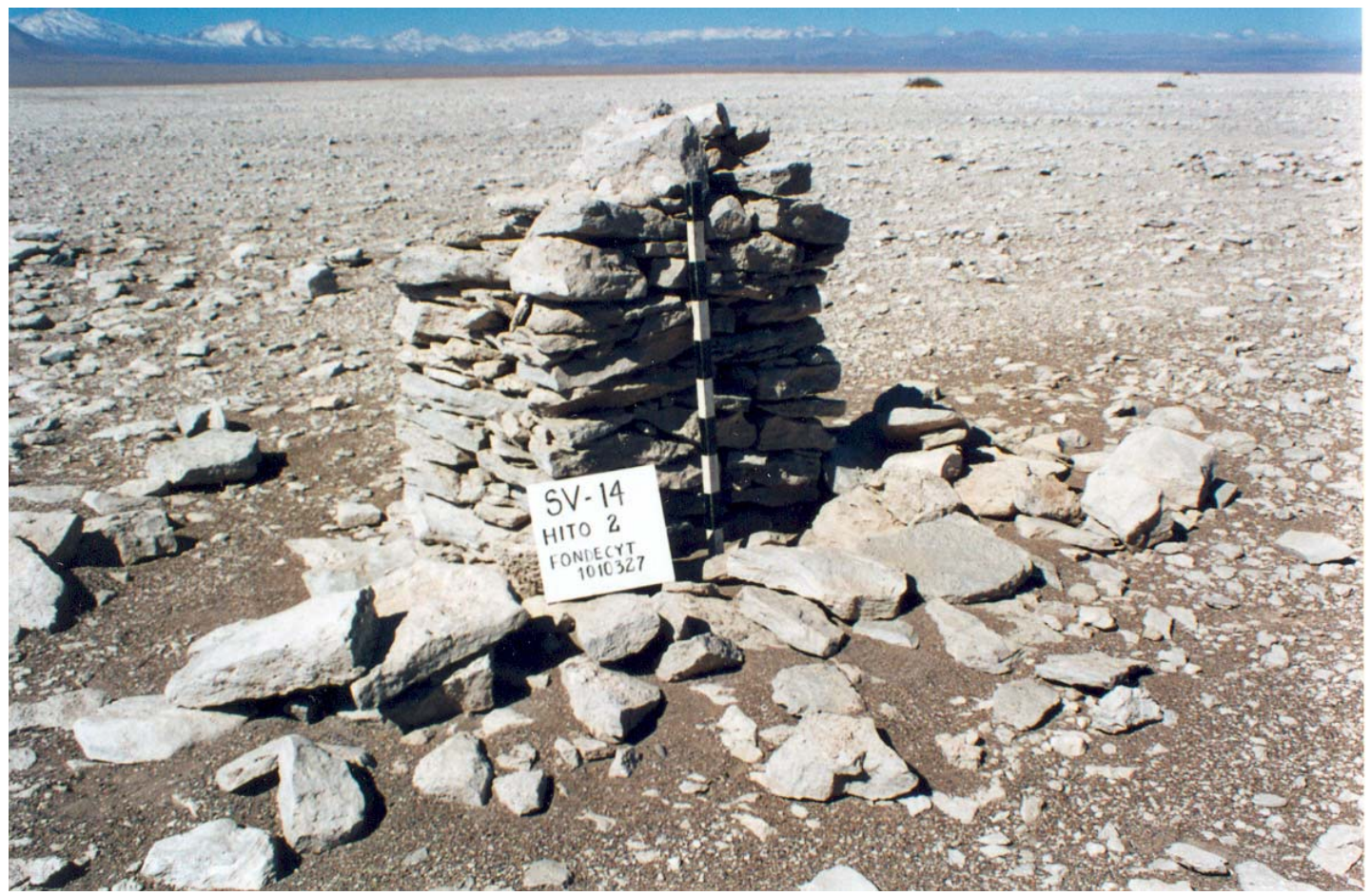

Figura 2. Detalle de hito en el camino incaico del río Loa (Lasana).

Detail of a landmark in the Inka road on the Loa river (Lasana). 


\section{Una Discusión desde la Etnohistoria. El Camino del Inka como un Sistema "Medido"}

Frecuentemente, el Capac Ñan es definido por los cronistas coloniales como un camino cuyas distancias estaban medidas y señalizadas. Guamán Poma destaca este aspecto, entre otros (como su ancho y su rectitud) como los que otorgaban una particular identidad a los caminos incaicos:

Con su legua y medida amojonado y señala$d o$, cada camino de ancho quatro uaras y por los dos lados puesto piedras que ua derecho, que no a hecho en todo el mundo los rreys como el Ynga (Guamán Poma, 1980:327. Aquí y siguientes citas, el destacado es nuestro).

Traducidas a categorías hispanas, estas mediciones y los hitos que las señalaban, fueron llamadas "leguas del Inka" y se les atribuyó una determinada equivalencia con las unidades de medición españolas:

Y en muchos lugares, como es en el Collao y en otras partes, avía señales de sus leguas, que eran como los mojones de España con que parten los términos, salvo que son mayores y mejor hechos los de acá: a estos tales llaman "topos" y uno dellos es una legua y media de Castilla (Cieza 1985:41).

Más abajo discutiremos la pertinencia de esta interpretación europea de los sistemas andinos de medición. Por de pronto, nos interesa destacar aquí que los caminos incaicos eran entendidos (por cronistas de tradición indígena y española) como un sistema vial "medido".

\section{El Tupu. Aproximaciones a la "Medida" Incaica}

El término topo o tupu, al parecer de origen cuzqueño, es el más frecuentemente asociado a los sistemas de medición incaicos. Se aplicaba tanto a superficies territoriales como a longitudes o distancias de camino. Sin embargo, tupu, tanto en quechua como en aymara, alude al concepto genérico de "medida", pero no corresponde necesariamente a una unidad de medición en particular (Bertonio 1984; González Holguín 1952:347).
La medición de superficies productivas en el mundo andino consideraba distintos factores relativos a la calidad y condiciones del suelo, a sus requerimientos técnicos, a la energía humana y al tiempo que su explotación requería. La extensión de un tupu, por tanto, era relativa y variable, y no correspondía a una dimensión preestablecida, como intentaron adjudicarle los españoles (Murra 1975:215). Al parecer, la voz tupu, que apela genéricamente a la "medida" o "medición" oficial cuzqueña, se había generalizado en los Andes con la expansión y la organización del sistema productivo estatal. De allí que sea la que aparece más frecuentemente asociada al camino Real o del Inka. Incluso, en la lengua aymara se utiliza el término tupu tanto para referir a la aplicación de este tipo de mediciones como para denominar al camino propiamente tal:

Tupu: Legua de Camino a la medida del Inka Tupu: Camino real Camino real: tupu (Bertonio 1984:113, 365) Si el camino estatal es caracterizado como un sistema "medido", ¿de qué categorías de medición de distancias se trata?

Una revisión preliminar de las categorías andinas de medición y una aproximación lingüística a las denominaciones aplicadas por el quechua y el aymara al respecto, nos introduce en un complejo campo de significados que parece operar o compartir ciertos principios similares.

\section{Tupus, Sayhuas, Chutas. \\ Categorías y Dispositivos de Medición y Demarcación del Espacio}

En quechua y sobre todo en aymara, las antiguas denominaciones relativas a formas de medición son múltiples y variadas (Rostworowski 1981). Sin embargo, destacan en ambas lenguas, además de tupu, las voces sayhua y chuta. En los vocabularios coloniales, estos términos (entre otros) incorporan dentro de un mismo campo semántico la "medición" y el "amojonamiento" de tierras o superficies y de distancias de camino. Generalmente se los relaciona con la técnica del apilamiento de piedras y, particularmente cuando se hace referencia a la vialidad estatal, son definidos como el "mojón" que indicaba las "leguas" del camino del Inka. 
Sayhua: Mojón de tierras

Sayhuani sayhuacuni: amojonar tierra, hacer linderos

Quellinca, sayhua, chuta: el montón de piedras puesto por mojón

Chuta Cazqui: la medida pública de tierras que era una braça

Chuta, Sayhua: término en cada cien braças de tierra en quadro. Y señal de las leguas

Chutatha, sayhuatha: ponerle y señalar las leguas de camino, como hazían en tiempo del Inga (Bertonio 1984; González Holguín 1952).

Aparentemente, el tupu, como concepto genérico se aplicó en las distintas regiones, respetando los mecanismos o prácticas de medición locales que tenían sus propias denominaciones (Murra 1975:214; Rostworowski 1981). Según la información entregada en 1542 por los quipucamayocs de Pacariqtambo, el Inka Viracocha les había ordenado "que hubiese topos de leguas en los caminos reales, por medidas de varas, que ellos llaman chotas [chutas]" (Urton 1984:37). Esta variedad de denominaciones, de la cual sólo hemos tomado algunas, permite suponer que los principios de medición, al menos aquellos relativos a los caminos, eran compartidos.

\section{La "Legua del Inka". Una revisión}

En su ilustración sobre los "caminos reales", Guamán Poma destaca la presencia de columnas de piedra asociadas a las rutas, que parecen representar los "mojones" o "topus" descritos por los cronistas (Figura 3). Sin embargo, aunque describe al Capac Ñan como un camino amojonado "con su legua y medida", no atribuye a esta última una extensión determinada (1992:326-327).

Como sostiene Rostworowski (1981:386), el tupu, como medida de distancia, no correspondía a una unidad de longitud preestablecida. Sus dimensiones variaban según la topografía y dificultad del terreno, y de acuerdo a la combinación de los factores tiempo y energía que implicaban los recorridos. Por otra parte, una serie de prácticas culturales podían determinar o incidir en la organización de los desplazamientos. Según la experiencia consignada por A. Raimondi en el Perú del siglo XIX, la administración de la energía humana a través del consumo de coca, podía constituir un criterio de medición de tiempos y distancias. El período de acción o efecto

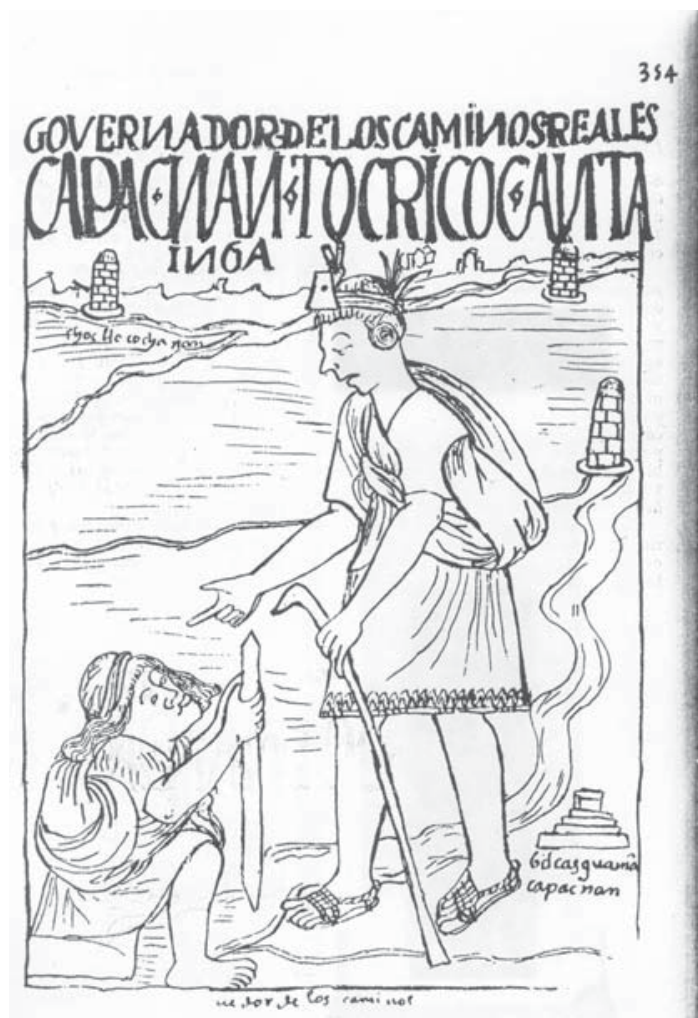

Figura 3. Estructuras de piedra asociadas a los caminos reales (Guamán Poma 1992:326).

Stone structures associated to royal Inca roads (Guamán Poma 1992:326).

que ésta tenía sobre el caminante -y la distancia recorrida en ese lapso- se denominaba "cocada", y representaba un principio o unidad de medición de acuerdo al cual se organizaban los trayectos y los lugares de descanso. Estos últimos, sin embargo, no parecen haber sido aleatorios, sino que estaban previamente establecidos a partir de criterios espaciales asociados a las prácticas rituales del viaje:

...tienen sus lugares fijos y determinados para hacer sus descansos y reemplazar la coca agotada con otra nueva; y como para esto escogen siempre un lugar algo abierto o la cumbre de una cuesta, sucede que unas cocadas son más largas que otras; en cuyo caso los he visto llegar sumamente fatigados al lugar de descanso... (Raimondi, citado por Rostworowski 1981:386).

El acto de "escupir" la coca para ofrendarla y cambiarla por otra nueva se realizaba en lugares 
distintivos y de evidente significación ceremonial. Incluso, en la actualidad, los lugares de descanso o "paradas" de los caravaneros altiplánicos se corresponden con los espacios destinados al ritual, convirtiéndolos en puntos de la ruta que organizan los itinerarios o jornadas de camino (Nielsen 1997:352, 355). En este sentido, distancia, tiempo, energía y ritualidad, podían ser factores o criterios estrechamente vinculados a las prácticas que regulaban, organizaban o "medían" el desplazamiento en los Andes.

Otra perspectiva para aproximarse a los significados de la "legua del Inka" proviene de la organización del sistema de chasquis o emisarios del Tawantinsuyu. Según se desprende de un litigio de tierras de 1583, chasqui o chasque, en el "reino Colla", remitía a una determinada unidad o referente para la medición de distancias. En sus declaraciones, los testigos indígenas utilizaban el chasque para contabilizar las distancias que separaban a un punto de otro. Tal pueblo o lugar se ubicaba a "poco menos que un chasque", o como a "tres chasques", o "como un chasque de los que ponía el inga" (Espinoza Soriano 1987:280).

Por cierto, esta categoría de medición presentaba dificultades a la administración española, que intentaba traducirla a sus sistemas propios de mensura, incurriendo en apreciaciones muy distintas. Varios cronistas definen al tири como la distancia que podía recorrer un chasqui a alta velocidad, y le asignan equivalencias a "un cuarto de legua", "media legua" o "legua y media" de las de Castilla (Santillán [1563] 1879:40; Guamán Poma 1992:323; Acosta [1590] 1954). Las Casas, por su parte, señalaba que el recorrido de los chasquis o "legua", abarcaba "mil pasos" (1892:170), y Murúa le asignaba también una medida más específica:

Caminaban corriendo y, cuando menos, quince o diez y seis leguas cada día y las leguas son larguísimas, según la cuenta del Ynga, porque llegan de cinco a seis mil pasos, y por caminos tan fragosos y ásperos... ([1613]1987:364).

Aunque el factor tiempo no era ajeno al sistema de mediciones europeas del siglo XVI (puesto que la "legua castellana" se basaba principalmente en la distancia caminada regularmente en una hora), se propendía a adjudicarle equivalencias en unidades menores como "pasos" o "varas". Las mediciones andinas que incorporaban, entre otros fac- tores, la energía o velocidad, difícilmente podían ser estandarizadas según estas categorías. Por otra parte, había una serie de otros criterios de carácter técnico, funcional, político y administrativo que relativizaban la distribución de los chasquis en los caminos y por tanto los recorridos que debían efectuar (Guamán Poma 1992:323; Murúa 1987:363). En definitiva, la diversidad de definiciones respecto a las dimensiones del tири о "legua del Inka" respondía a la multiplicidad de factores que, en la práctica, lo determinaban. Si los tupus incaicos estaban señalizados, su distribución no podía obedecer a patrones rígidos y regulares.

\section{Los "Hitos" del Camino y una posible Nomenclatura Vial}

En sus distintas versiones, los españoles señalaban que los tupus o "leguas del Inka" equivalían a fracciones de la legua castellana, o a extensiones mucho mayores a ella. Según Las Casas, los conquistadores españoles que se aventuraban por el Camino del Inka hacia Chile se quejaban de que éste era muy extenso y agotador, puesto que abarcaba "mill y tantas leguas largas" (1892:162), lo que sugiere que esas "leguas" estaban señalizadas y que, de alguna manera, constituían un referente para la medición o percepción de las distancias que debían recorrer. Cristóbal de Molina, que viajó con Almagro por los caminos del Collasuyo, y por el Despoblado de Atacama, menciona estas "señales" como indicadores de distancia e incorpora el factor tiempo como unidad de referencia para su interpretación:

...y en algunas partes de este camino, especialmente de esta la ciudad del Cuzco adelante, hacia el estrecho de Magallanes y provincias de Chile, va señalada en el camino la media legua y la legua; por manera que sin reloj ni otra cuenta sabe el hombre a cada paso adonde va y lo que ha caminado (1895:440).

La ruta de Atacama, y particularmente el camino del Despoblado, no obstante sus condiciones extremadamente áridas e inhóspitas, fue la vía más expedita y directa de comunicación administrativa entre la capital incaica del Cuzco y la región de Chile (Hyslop 1992). De allí que es muy posible que este tipo de demarcaciones esté particularmente asociado a la organización del sistema de chasquis. Según un documento anónimo fechado en 1534, 
existían en los caminos incaicos de la región del Cuzco unos "pilares", dispuestos de trecho en trecho, que señalaban los tramos que debía recorrer cada "indio de correo". Aparentemente se trataba de estructuras más sofisticadas que las que se observan en Atacama, puesto que operaban como una especie de miradores, sobre cada uno de los cuales se apostaba un chasqui. Una vez recibido el mensaje, éste debía correr a alta velocidad la distancia que lo separaba del pilar siguiente (Porras Barrenechea 1967:64). Aunque parece improbable que los hitos de Atacama hayan cumplido la función de miradores, la referencia citada sugiere la posible asociación de este tipo de dispositivos con la tarea de los mensajeros del Inka y con una determinada organización del sistema vial que orientaba, medía o regulaba sus desplazamientos.

Un estudio detenido y especializado sobre la frecuencia y disposición de estas estructuras, que incorpore algunos de los criterios señalados, podría arrojar más elementos a esta discusión. Por de pronto, podemos sostener que los sistemas de "medición" andinos poco tenían que ver con las lógicas europeas de organización y sistematización del espacio, por lo que intentar establecer regularidades en la distribución de los hitos y equivalencias con sistemas de medición españoles (Hyslop 1992:174), no puede constituir el punto de partida para su análisis e interpretación.

\section{Mediciones, Deslindes y Territorialidades en el Camino del Inka}

Los antecedentes etnohistóricos respecto a las posibles funciones de los hitos o tupus de los caminos incaicos, no hacen sino complejizar aún más estas interpretaciones iniciales. Aparentemente, en ciertos casos, éstos fueron erigidos para establecer deslindes territoriales y, eventualmente también, para segmentar la vía de acuerdo a la organización de la mita "caminera" que correspondía a cada ayllu o grupo social tributario. Las características que pudieron haber tenido los "amojonamientos" del Inka en las distintas regiones o "provincias", requieren de una discusión profunda respecto a las categorías espaciales, políticas y rituales que organizaban el dominio territorial incaico. Aunque por razones de espacio no podemos profundizar en esto, nos interesa discutir, desde el registro arqueológico y etnohistórico, la aparente presencia de deslindes incaicos en los caminos de Atacama y sus posibles ámbitos de significados.

\section{Hileras o líneas de Hitos. Los casos de Lasana y de Vaquillas}

Durante nuestra participación en la prospección del camino incaico del río Loa, pudimos reconocer, a unos $14 \mathrm{~km}$ al norte de Lasana, una serie de hitos dispuestos en línea recta y perpendicular al camino. Se trataba de un alineamiento de estructuras troncopiramidales que dibujaba una línea transversal, en una orientación aproximada EsteOeste y en plena pampa desértica. Los dos hitos centrales, ubicados en ambos costados de la vía, estaban separados entre sí por unos $7 \mathrm{~m}$ y alcanzaban una altura de 1,20 m. La hilera o línea, compuesta por siete hitos identificables desde el camino, abarcaba una distancia algo superior a $1 \mathrm{~km}$. Hacia el Este, se divisaba un octavo hito, ubicado en la ladera opuesta del cañón del Loa, y a aproximadamente $2 \mathrm{~km}$ del camino (Figura 4) (Berenguer et al. 2004).

Esta singular forma de intervención y demarcación del espacio, que trascendía al trazado vial, se ha identificado también en el registro arqueológico y en la documentación histórica del camino incaico del Despoblado de Atacama. En su prospección efectuada en 1981, Niemeyer y Rivera destacan la ubicación de tres hitos de estructura cuasi tronco piramidal dispuestos en línea perpendicular y por medio de dos de los cuales pasaba el camino. Se encontraban en el sector denominado Llano Alto de Vaquillas, extensa planicie sobre los 4.000 metros de altura. Estaban separados entre sí por 25 y 20,5 m, y el mejor conservado presentaba una altura de 1,10 m. Los arqueólogos establecieron su filiación incaica por su alineamiento con respecto al camino, por su estructura formal, correspondiente al patrón identificado en el resto de los "topus" del trayecto; y por el contexto arqueológico, ya que se trataba de una zona de activo tráfico prehispánico y abundante de cerámica incaica (Niemeyer y Rivera 1983:112, 140).

Por la detallada descripción de los autores respecto a su ubicación, es posible constatar que se trataba de las llamadas "pirámides" o "columnas" del Despoblado de Atacama, documentadas en el siglo XVIII como un deslinde jurisdiccional colonial. Efectivamente, la ruta incaica del Despoblado había seguido siendo utilizada por el sistema de correos y, en las Reales Ordenanzas que lo regulaban en 1778 , se señalaba a estos hitos como las "pirámides que dividen las jurisdicciones del Rey- 


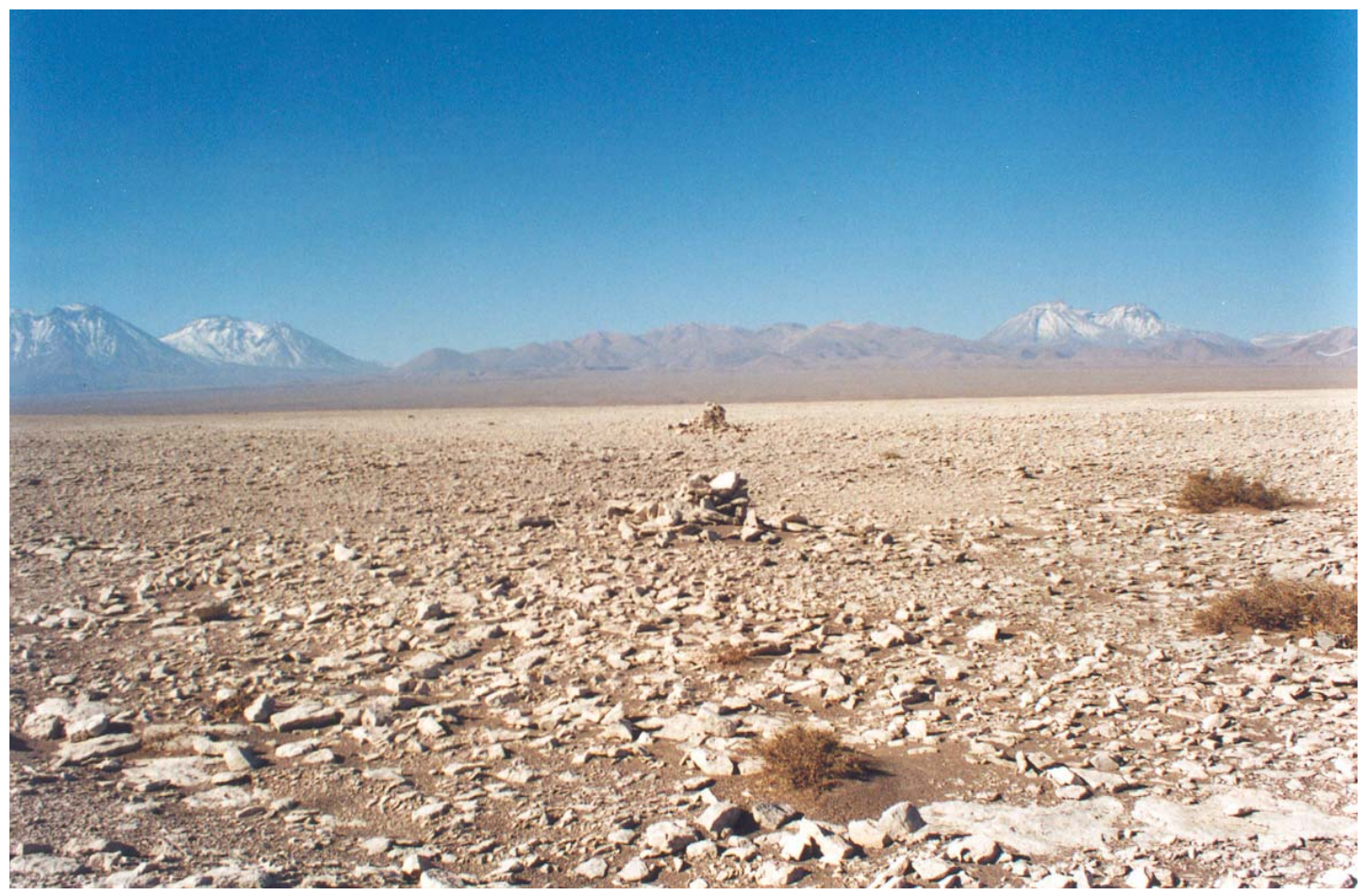

Figura 4. Alineamiento de hitos en el camino incaico al norte de Lasana. Perspectiva hacia el Este, en dirección al cañón del río Loa. Alignment of landmarks in the Inca road north of Lasana. View toward the east and the Loa river canyon.

no del Perú con el de Chile" (Bertrand 1885:162). Durante el siglo XIX, diversas expediciones oficiales realizadas en la región mencionan estas "columnas", puesto que al estar documentadas como deslindes coloniales fueron objeto de confrontación diplomática entre Bolivia y Chile. Bertrand (1860:39) las describía como "mojones de piedra, como las apachetas de los indios" (1885:289). Philippi, como "montones de piedra" dispuestos en línea, aproximadamente en dirección Este-Oeste, y las identificaba como pertenecientes al Camino del Inka. Por su parte, el jurista boliviano J.M. Santibáñez, señalaba que estas columnas eran numerosas y que formaban una larga serie que podía apreciarse con la vista hasta una considerable distancia (Sanhueza 2002:125-126). Se desprende, entonces, que los hitos de Vaquillas eran originalmente más numerosos que lo que pudieron registrar los arqueólogos en la década de 1980, posiblemente porque en su mayoría habían sido destruidos.

Estas no son, sin embargo, las únicas referencias documentales que conocemos respecto a la existencia de estas demarcaciones. Como propusimos en un artículo anterior (Sanhueza 2002), la tradición oral de los siglos XVI y XVII asociaba este extenso tramo del camino del Despoblado al volcán Llullaillaco, importante santuario de altura o guaca estatal. Según López de Velasco, cosmógrafo oficial de la corona española en 1571, se encontraban en la región del Llullaillaco "los mojones altos y grandes que dividían las provincias de Chile de las del Pirú en tiempo de los Ingas" (Sanhueza 2002:117). Es muy posible que esta referencia esté aludiendo a las "pirámides", "columnas" o "topus" consignados y descritos por quienes recorrieron el camino en los siglos XVIII, XIX y XX. De ser así, se estaría otorgando a estas estructuras no sólo un origen incaico, sino también la calidad de deslinde "provincial". Pero, ¿cuál es el concepto de "provincia" allí esgrimido?

La excepcional oportunidad de comparar dos situaciones viales con estructuras demarcatorias similares, ubicadas en lugares tan distantes entre sí (como es el caso de Vaquillas y Lasana), y de documentar históricamente, al menos una de ellas, permite generar un espacio de discusión respecto a las posibles categorizaciones espaciales y estrategias políticas de dominio que podrían estar operando en este tipo de demarcaciones. 


\section{"Medir", “Amojonar", "Repartir". La Organización del Espacio Productivo}

Las reorganizaciones espaciales incaicas suelen ser descritas como producto de un proceso de medición, amojonamiento y repartición de los territorios y recursos (Betanzos 1987:55-56, 116; Sanhueza 2002). Según el cronista Blas Valera, las tierras de labor, las dehesas, los montes, las minas, las salinas, los lagos y ríos...

Todas estas cosas -y otras muchas- mandaba que se contasen y midiesen y se asentasen por memoria cada una de por sí: primeramente las de toda la provincia, luego las de cada pueblo y a lo último las de cada vecino (...) Además mandaba que conforme a la cuenta y medida que se había hecho de la provincia, le pusiesen sus mojoneras y linderos para que estuviese dividida de sus comarcanas" (Garcilaso 1995:282).

Guamán Poma describe toda una política estatal de amojonamiento y medición a nivel local y "provincial", ejecutada por dos funcionarios o "jueces" de jerarquía cuzqueña (el "mojonador y medidor") que tenían a su cargo la distribución de las tierras y recursos entre la población, asegurando el usufructo estatal de una porción de ellos. Estos funcionarios recibían el nombre de Sayhua checta suyoyoc. El significado de la expresión se relaciona con "mojón" o "lindero" (sayhua); con "partir" o "dividir" (checta); y con quien administra o reparte los suyus (González Holguín 1952; Guamán Poma 1992:325) (Figura 5).

Según los diccionarios quechuas de los siglos XVI y XVII, suyu constituía una categoría política, social y espacial, estrechamente vinculada con la organización de la mita estatal. La voz suyu apelaba a una determinada organización jurisdiccional, al ordenamiento, registro y división de recursos humanos y productivos, y a la distribución del espacio para el trabajo colectivo:

Suyu: Provincia

Suyu quiti: La tierra de jurisdicción de cada juez Prouincias o términos o jurisdicciones de juezes: Sиуи sиyи, o suyи quimray, o suyuquiti

Suyuchanacuni: ponerse en renglera, o en orden así en pie, o en sus asientos para ordenarlos Suyuchacuni: Ponerse a parte cada ayllo, o diuidirse

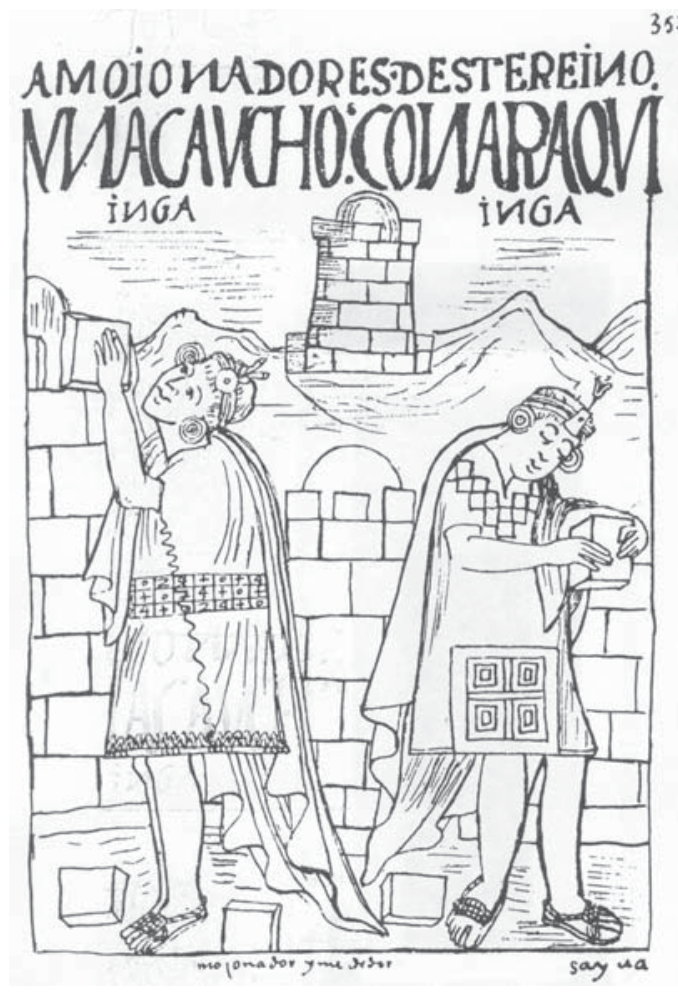

Figura 5. El mojonador y medidor del Inka según Guamán Poma (1992:324).

The landmaker and surveyor of the Inka, according to Guamán Poma (1992:324).

Suyucuni, gui: Hacer partes dividiendo

Suyo: Parte así divisa

Sиуи: Lo que cabe de parte de trabajo a cada un suyo o persona

Suyuni: Dividir tierras chacaras, obras, dar partes del trabajo

(González Holguín 1952; Santo Tomás [1560] 1951).

Sиyи remitía también a un determinado ordenamiento lineal del espacio, asociado a la noción de "banda"o "franja", como señalan los vocabularios coloniales y los estudios semióticos de la textilería andina (González Holguín 1952:334, 688; Cereceda 1978). Recogiendo esta interpretación, Wachtel advierte que la distribución territorial de los suyus para la mita agrícola en la región de Cochabamba, había sido organizada y amojonada por el Inka en "franjas de terreno" que, dispuestas en forma transversal al valle, señalaban y dividían los espacios de trabajo que correspondía a cada grupo o "nación" de mitimaes y de mitayos (1980:300-303). 
La distribución de las faenas colectivas y la división de suyus, se organizaba de acuerdo a un acto previo de "medición" de lo que tocaba a cada unidad o unidades sociales:

... aunque muchas parçialidades vayan a hazer una cosa de comunidad nunca la empieçan sin ver y medir lo que cabe a cada una y entre los mismos de cada parcialidad tanbién hazen su diuision que llaman suyos... (Polo de Ondegardo, citado por Murra 1975:28).

La distribución estatal de los suyus se realizaba considerando las condiciones ecológicas, productivas y demográficas de cada región. El Inka mandaba que "se contasen y midiesen" todos los recursos de cada "provincia", pueblo o ayllu y aplicaba criterios o principios de medición, según una determinada proporcionalidad entre los recursos y la fuerza de trabajo disponibles. El "igualar", o repartir "por medida igual" o proporcional el trabajo, constituía uno de los principios rectores de la distribución de los suyus (Valera, citado por Garcilaso 1995:408). Sus dimensiones territoriales, dice Betanzos (1987:116), eran sancionadas por el Inka, quien luego de cada conquista, mandaba que "le enviasen en pintura el arte y manera de las tales tierras y provincias" para "igualarlas" y "amojonarlas".

La estrecha asociación entre los conceptos de "amojonamiento" y de "medición", nos remiten nuevamente a la terminología ya descrita (tupu, sayhua y chuta), que refieren a sistemas de medición de distancias y también de superficies territoriales. Las relaciones semánticas y las connotaciones sociales de estos conceptos, se presentan en forma particularmente más elocuente al referir o traducir las distintas acepciones del término chuta. Al respecto, el diccionario aymara de Bertonio (1956:94) nos remite a un complejo sistema, no sólo de medición, sino también de prácticas sociales y productivas estrechamente relacionadas. Define chuta como señal de las leguas del camino del Inka; como mojón de piedra para división de las tierras; como medida de superficie, y como sinónimo de mitta o "vez", aludiendo al concepto de turno para el trabajo colectivo (Urton 1984). En quechua, chuta refiere a una medida de tierras, pero además a determinados instrumentos de medición, como la soga o los brazos extendidos (González Holguín 1952:125). Estas asociaciones adquieren mayor sentido a tra- vés de la experiencia etnográfica desarrollada por Gary Urton (1984).

\section{Sistemas de Medición y Estrategias de Interacción Social}

A partir de su investigación en la comunidad quechua de Pacariqtambo, Urton analiza el concepto local de chuta como una práctica social de medición y distribución espacial del trabajo comunitario. Se denomina chutas a las secciones, tramos o franjas de territorio que se asignan a cada ayllu de la comunidad en la distribución anual de trabajos agrícolas, construcción de infraestructura pública, limpia de canales y habilitación o reparación de caminos.

Las chutas no son unidades de extensión predeterminada. Sus dimensiones varían según el tamaño de cada ayllu, es decir, de acuerdo a la cantidad de fuerza de trabajo con que cuenta y al tiempo que deberá invertir. Para salvaguardar una distribución equilibrada de estas obligaciones, la extensión de cada una de estas secciones es producto de una activa negociación, realizada en un contexto ritualizado y festivo de la comunidad. Eventualmente, se utilizan determinados implementos, como la manipulación de una cuerda, que más que una unidad de medición, constituye un instrumento que permite alcanzar una determinada proporcionalidad en la asignación de las chutas, según el tamaño de cada unidad social. La distribución culmina, finalmente, en un consenso respecto a la "medida" que parece justa y que implica "iguales" condiciones de trabajo. Se trata de una instancia ritualizada que regula las faenas colectivas y que combina prácticas de interacción social con ciertos principios de organización y división del espacio. La extensión de cada chuta se establece a partir de criterios sociales, económicos y políticos flexibles y no predefinidos por la aplicación de un sistema estandarizado de medición (Urton 1984).

Recogiendo las referencias de Wachtel respecto al ordenamiento espacial de los suyus de Cochabamba, Urton describe las chutas de Pacariqtambo como "franjas" de terreno, establecidas a través de virtuales líneas rectas o líneas imaginarias que ordenan y dividen ritualmente los espacios públicos de trabajo. Según el autor, este sistema podría constituir un modelo para intentar comprender las formas prehispánicas de distribución espacial que operaban en instituciones sociales, políticas y rituales como los suyus y ceques del Cuzco (Urton 1984:13, 37, 55-56). 
Compartimos con el autor que los conceptos de chuta y de suyu parecen obedecer a principios similares de medición y de organización del espacio social. Suyu, asociado más explícitamente a la estructura territorial incaica, podría estar remitiendo a una institucionalización de estas prácticas andinas a nivel de la mita estatal. En ese sentido, el concepto actual de chuta, dinámico y flexible, pudo haber sido incorporado como estrategia de negociación política por el Tawantinsuyu. Sin embargo, chuta, al igual que suyu en el siglo XVI, refieren también al "amojonamiento" del Inka. Aparentemente, en el marco de un sistema estatal de dominación, el ordenamiento o el "diseño" espacial del Inka adquirió un carácter cada vez más rígido, permanente e impositivo.

\section{Demarcaciones Lineales y Suyus}

Es difícil establecer un límite o frontera entre los ámbitos propiamente políticos, productivos y ceremoniales en la organización del estado incaico. Según Cobo, las tierras y recursos de cada pueblo y "provincia" se repartían y amojonaban, dividiendo aquellas dedicadas a las guacas, al Inka y a la comunidad. Las tierras eran trabajadas por las autoridades locales con sus "comunes" quienes "repartían entre sí por rayas las tareas que a cada uno cabía trabajar, la cual tarea o medida llamaban suyu" (Cobo [1653] 1964:121).

Las líneas demarcatorias que observamos en los caminos incaicos de Atacama, podrían obedecer a ciertos principios institucionalizados de organización de espacios sociopolíticos, socioproductivos y/o rituales. Desde esa perspectiva, es significativo que los vocabularios de los siglos XVI y XVII asocien semánticamente el concepto incaico de ceque, como línea divisoria, con la práctica institucionalizada de "amojonar", "medir" y "repartir":
Sayhuani, sayhuacuni: amojonar tierras, hacer linderos

Sayuac o cequec: deslindador

Cequeni. gui o sayuani. gui: deslindar heredad o diuidirla con lindero

Ceqque: raya, línea, término

Ceqqueni: rayar, linear, deslindar

Allpa: La tierra de labor y el suelo

Allpa tupuk apu, o cequek apu: medidor o repartidor de tierras (González Holguín 1952; Santo Tomás 1951).

\section{A Modo de Recapitulación}

El sistema de "amojonamiento" o demarcación incaico formó parte de una política de organización o reorganización de los territorios sometidos que habría operado a partir de estrategias e instituciones andinas socialmente arraigadas. El término "medir" parece ser la traducción española a una serie de prácticas de distribución del espacio social y productivo, así como de organización del desplazamiento y las comunicaciones en un extensísimo territorio. El Capac Nan representaba uno de los ejes que ordenaban y articulaban el sistema de control y dominio del Tawantinsuyu y, en ese contexto, los "hitos", "mojones" o tupus del camino no parecen ser elementos azarosos del trazado vial. Su distribución irregular, así como su presencia diferenciada como hitos solitarios, en pares o en hileras, sugiere que se trataba de estructuras cargadas de significado y que pudieron comportarse como elementos polisémicos, respondiendo a distintos significados o funcionalidades según el contexto y las características con que se presentaran.

Agradecimientos: Esta investigación fue financiada por el Proyecto FONDECYT $\mathrm{N}^{\circ}$ 1010327 "Arqueología del sistema vial de los Inkas en el Alto Loa, II Región”, dirigido por José Berenguer R.

\section{Referencias Citadas}

Acosta, J. de

1954 [1590] Historia natural y moral de las Indias Biblioteca de Autores Españoles, T. LXXIII. Atlas, Madrid.

Berenguer, J., I. Cáceres, C. Sanhueza y P. Hernández 2004 El Qhapaq Ñan en el Alto Loa. Región de Antofagasta. Un estudio micro y macro arqueológico. Estudios Atacameños, (en prensa).
Bertrand, A.

1885 Memoria sobre la exploración a las cordilleras del desierto de Atacama. Anuario Hidrográfico de la Marina de Chile Año X:4-299.

Bertonio, L.

1984 [1612] Vocabulario de la Lengua Aymara. Ediciones Ceres, Cochabamba. 
Betanzos, J. de

1987 [1557] Suma y Narración de los Inkas. Edición a cargo de M.C. Martín Rubio. Ediciones Atlas, Madrid.

Cereceda, V.

1978 Semiologie des tissus andins: Les talegas d'Isluga. Annales ESC, 33(5-6).

Cieza de León, $\mathrm{P}$.

1985 [1553] Crónica del Perú (Segunda Parte) o Señorío de los Incas, Pontificia Universidad Católica del Perú, Lima.

Cobo, B.

1964 [1653] Historia del Nuevo Mundo. Biblioteca de Autores Españoles, T. XCII, Vol. II. Atlas, Madrid.

Espinoza Soriano, W.

1987 Migraciones internas en el reino Colla. Tejedores, plumereros y alfareros del Estado Imperial Inca. Chungara 19:243-289.

Garcilaso de la Vega, I.

1995 [1604] Comentarios Reales de los Incas. Edición, índice analítico y glosario de Carlos Araníbar. Fondo de Cultura Económica, México.

González Holguín, D.

1952 [1608] Vocabulario de la Lengua de todo el Perú Llamada Lengua quichua o del Inca. Universidad Nacional de San Marcos, Lima.

Guaman Poma de Ayala, F.

1992 [1614] Nueva Corónica y Buen Gobierno. Edición a cargo de J. Murra y R. Adorno. Siglo XXI Editores, México.

Hyslop, J.

1992 [1984] QhapaqÑam, el Sistema Vial Incaico. Instituto Andino de Estudios Arqueológicos, Lima.

Las Casas, B. de

1892 De las Antiguas Gentes del Perú. Tipografía de Manuel G. Hernández, Madrid.

Lynch, T.

1995 Inka roads in the Atacama: Effects of later use by mounted travellers. Diálogo Andino 14/15.

Molina, C. de

1895 Conquista y población del Perú. José Toribio Medina (Ed.) Colección de Documentos Inéditos para la Historia de Chile, Tomo VII, Santiago.

Murra, J.

1975 Formaciones Económicas y Políticas del Mundo Andino. I.E.P, Lima.
1999 [1978] La Organización Económica del Estado Inca. Siglo XXI Editores, México.

Murúa, M. de

1987 [1613] Historia General del Perú. Manuel Ballesteros (Ed.), Historia 16, Madrid.

Niemeyer, H. y M. Rivera

1983 El camino del Inca en el despoblado de Atacama. Boletín de Prehistoria de Chile 9.

Nielsen, A.

1997 El tráfico caravanero visto desde La Jara. Estudios Atacameños 14:339-371.

Pease, F.

1978 Del Tawantinsuyu a la Historia del Perú. I.E.P., Lima.

Philippi, R. A.

1860 Viaje al Desierto de Atacama hecho en Orden del Gobierno de Chile en el Verano de 1853-54, Librería de Eduardo Anton, Halle, Sajonia.

Porras Barrenechea, R.

1967 Relación francesa de la conquista del Perú. En Las Relaciones Primitivas de la Conquista del Perú., editado por R. Porras Barrenechea, Instituto Raúl Porras Barrenechea, Lima.

Rostworowski, M.

1981 Mediciones y cómputos en el antiguo Perú. En La Tecnología en el Mundo Andino. Runakunap Kawsayninkupaq Rurasqankunaqa. Tomo I. Universidad Nacional Autónoma de México, México.

Sanhueza, C.

2002 En busca del Gran Mentiroso: Relatos orales, demarcaciones territoriales. El Camino del Inka en el despoblado de Atacama. Revista de Historia Indígena 6.

Santillán, F. de

1879 [1563] Relación del origen, descendencia, política y gobierno de los Incas. Por el Licenciado Fernando de Santillán. En Tres Relaciones de Antigüedades Peruanas. Ministerio de Fomento, Madrid.

Santo Tomás, D.

1951 [1560] Lexicón. Edición Facsimilar, Instituto de Historia, Universidad Nacional de San Marcos, Lima.

Urton, G.

1984 Chuta: El espacio de la práctica social en Pacariqtambo, Perú. Revista Andina 2(2).

Wachtel, N.

1980 Les mitimas de la vallée de Cochabamba. La politique de colonisation de Huayna Capac". Journal de la Société des Americanistes, LXVII. 